\title{
Differential Adhesion of Pseudomonas aeruginosa to Human Respiratory Epithelial Cells in Primary Culture
}

\author{
M. C. Plotkowski, ${ }^{\star *}$ M. Chevillard, ${ }^{*}$ D. Pierrot, ${ }^{*}$ D. Altemayer, ${ }^{\star}$ J. M. Zahm, ${ }^{\star}$ G. Colliot, * and E. Puchelle* \\ *Institut National de la Santé et de la Recherche Médicale U.314, Hôpital Maison Blanche, 51092 Reims Cédex, France; \\ and ${ }^{\ddagger}$ Department of Microbiology and Immunology, Universidade do Estado Rio de Janeiro, 20550 Rio de Janeiro, Brazil
}

\begin{abstract}
Human nasal polyps in outgrowth culture were used to study the Pseudomonas aeruginosa adhesion to respiratory cells. By scanning electron microscopy, $P$. aeruginosa were seen associated with ciliated cells, but by transmission electron microscopy, bacteria were never seen at the interciliary spaces or attached along cilia, but were identified trapped at the extremities of cilia, usually as bacterial aggregates. A fibronectin-containing fibrillar material was seen associated with aggregated bacteria. By time-lapse video microscopy, bacteria were seen to aggregate in the culture medium following their addition to the culture wells. Progressively, these aggregates were trapped by cilia or attached to migrating cells of a lower cell layer that protruded beneath the upper layer cells, at the outgrowth periphery. $P$. aeruginosa adhesion to these lower cell layer migrating cells was significantly higher than to ciliated or nonciliated cells of the upper cell layer. Migrating cells were intensely labeled by the complexes Con $A$ and arachis hypogea agglutinin (PNA)-FITC, in contrast to the other cells. The percentage of PNA-labeled cells with attached bacteria was significantly higher than that without bacteria. These results suggest that changes of cell surface glycoconjugates related with cell migration may favor $P$. aeruginosa adhesion to respiratory cells. (J. Clin. Invest. 1991. 87:2018-2028.) Key words: migrating cells $\bullet$ fibronectin $\bullet$ outgrowth culture $\bullet$ lectin cytochemistry $\bullet$ respiratory mucin
\end{abstract}

\section{Introduction}

An intriguing feature of Pseudomonas aeruginosa is the capability to cause persistent respiratory infection in patients with chronic diseases of the lungs, such as chronic bronchitis, bronchiectasis, and, more typically, cystic fibrosis $(C F)^{1}(1)$. Histo-

Part of this work was presented at the Meeting of the American Thoracic Society in Boston, MA, 20 May 1990.

Address correspondence to Dr. M. C. Plotkowski, Institut National de la Santé et de la Recherche Médicale U. 314, Hôpital Maison Blanche, 45, rue Cognacq-Jay, 51092 Reims Cédex, France.

Received for publication 9 July 1990 and in revised form 13 December 1990

1. Abbreviations used in this paper: $\mathrm{CC}$, ciliated cells; $\mathrm{CF}$, cystic fibrosis; FN, fibronectin; IF, immunofluorescent; LCL, lower cell layer; NCC, nonciliated cells; PNA, arachis hypogea agglutinin; SEM, scanning electron microscopy; TEM, transmission electron microscopy; WGA, wheat germ agglutinin.

J. Clin. Invest.

(C) The American Society for Clinical Investigation, Inc.

$0021-9738 / 91 / 06 / 2018 / 11 \quad \$ 2.00$

Volume 87, June 1991, 2018-2028 pathological studies demonstrate that erosion of the respiratory epithelium is a common finding in these patients (2). Injury of the respiratory mucosa has been shown to enhance $P$. aeruginos $a$ adhesion, and so potentially favors the persistence of infection by exposing previously masked receptors for bacterial adhesins (3). Nevertheless, other factors may be involved in the chronic $P$. aeruginosa colonization and/or infection of respiratory airways.

Epithelial regeneration is a basic response to injury, fundamental for the maintenance of epithelial barrier function. Regeneration of hamster tracheal epithelium after mechanical injury has been shown to begin by spreading and migration of viable cells at the wound margins to cover the denuded lesions (4). Thereafter, a wave of epithelial cell divisions occurs in such a way that, by $48-72 \mathrm{~h}$, the injured site is covered by a layer of undifferentiated cells. The last event that renders the regenerated epithelium indistinguishable from the normal is the cellular differentiation into ciliated or secretory cells.

Apical cell-surface carbohydrates have been shown to be altered during cellular differentiation $(5,6)$. Cell surface sugars on epithelial cells spreading and/or migrating to cover a wound have also been shown to differ from sugars found on normal epithelial cells $(7,8)$.

Bacterial adhesion to host cells may arise from direct molecular interaction between bacterial adhesins and host glycoconjugate receptors from the plasma membrane glycocalyx (9). Therefore, it may be hypothesized that the presence of receptors for microbial adhesins may vary during epithelial regeneration and cell differentiation after injury. Our previous results (10) showing that pneumococcal adhesion to respiratory epithelium is maximal in late repair phase following influenza $A$ virus injury of the respiratory mucosa support this hypothesis.

The differentiation of respiratory epithelium in primary cell culture has been shown to recapitulate the epithelial repair following injury in hamsters (11). We have recently developed a human nasal polyp primary culture allowing the study of ciliogenesis and in vitro functional activity of respiratory cilia during their maturation (12). This culture model provides an exciting approach for the study of $P$. aeruginosa adhesion to human respiratory epithelial cells during the process of migration, growth and differentiation.

In this study, we report a region-specific distribution of $P$. aeruginosa on respiratory cells in culture. A high percentage of bacteria was found on cells of the lower cellular stratum of the multilayered culture, especially on migrating cells of the periphery of the culture. Therefore, these cells appear as potential candidates for bacterial adhesion.

\section{Methods}

Bacteria. Two nonmucoid $P$. aeruginosa strains, isolated from expectorated sputum from a $C F\left(P_{24}\right)$ and a non-CF patient $\left(P_{10}\right)$, were maintained in $20 \%$ glycerol in Trypticase Soy Broth (Biolyon, Dardilly, 
France) at $-20^{\circ} \mathrm{C}$ until used. $P_{24}$ was not serotypable while $P_{10}$ belonged to the serogroup 0:10 (Diagnostic Pasteur, Paris). For adherence assays, the stock suspensions were thawed and bacteria cultured overnight in Trypticase Soy Broth at $28^{\circ} \mathrm{C}$, without shaking, to stimulate fimbriation. The presence of fimbriae was controlled by placing a drop of $P$. aeruginosa cultures on collodion-coated grids, staining with 5\% uranyl acetate for $3 \mathrm{~min}$, and by examining with a Jeol $200 \mathrm{CX}$ transmission electron microscope. Bacterial cells were harvested by centrifugation and suspended in RPMI 1640 medium containing $20 \mathrm{mM} \mathrm{N}$-2hydroxylethyl piperazine- $N$ '2 ethane sulphonic acid (RPMI-Hepes medium). The absorbance of the $P$. aeruginosa suspensions at $640 \mathrm{~nm}$ was adjusted to $\sim 0.5$ which corresponded to a concentration ranging from 5 to $9 \times 10^{8} \mathrm{CFU} / \mathrm{ml}$. Immediately before the adherence assays, bacteria were dispersed with a 5-ml syringe fitted with a 25 -gauge needle.

Epithelial cell culture. Nasal polyps were removed from patients undergoing nasal polypectomy due to nasal obstruction. Epithelial cell cultures were performed as described (12). Briefly, small explants were cut out from the nasal polyps and seeded onto type I collagen-coated circular glass coverslips in 24-well culture plates containing a defined RPMI 1640 medium (supplemented with insulin $1 \mu \mathrm{g} / \mathrm{ml}$, transferrin 1 $\mu \mathrm{g} / \mathrm{ml}$, epithelial growth factor $10 \mathrm{ng} / \mathrm{ml}$, hydrocortisone $0.5 \mu \mathrm{g} / \mathrm{ml}$, and retinoic acid $10 \mathrm{ng} / \mathrm{ml}$ ). Cultures were incubated at $37^{\circ} \mathrm{C}$ under humidified $5 \% \mathrm{CO}_{2}$-air mixture. Under these conditions, epithelial cells migrated from the explants and gave origin to an outgrowth area around the explants.

SDS-PAGE performed on the collagen used in the culture model revealed only type I collagen $\alpha$ and $\beta$ bands, without any other contaminant proteins.

Adherence assays. On day 4 to 6, the supplemented RPMI medium of the culture wells was eliminated and replaced by $200 \mu$ l of the $P$ aeruginosa suspension in RPMI-Hepes medium prepared as described above. Cultures were incubated for $1 \mathrm{~h}$ at $37^{\circ} \mathrm{C}$, rinsed four times under mild manual agitation with $0.5 \mathrm{ml}$ PBS $0.1 \mathrm{M}, \mathrm{pH} 7.2$, and fixed with $2.5 \%$ glutaraldehyde in PBS for $2 \mathrm{~h}$ at $4^{\circ} \mathrm{C}$, unless otherwise stated.

Electron microscopy. Glutaraldehyde-fixed epithelial cells were rinsed with PBS and dehydrated through graded ethanols. For scanning electron microscopy (SEM), cultures were critical point dried, coated with gold palladium, and examined on a Philips 525 SEM. For transmission electron microscopy (TEM), cells were embedded in Epon 812. Ultrathin sections were stained with uranyl acetate and lead citrate, and examined with a Hitachi H300 TEM.

Quantitation of $P$. aeruginosa adherence. In each of the outgrowth cultures examined, adherent bacteria were localized and quantified by SEM observation of at least 150 consecutive microscopic fields using a constant magnification $(2,700)$, a working distance of $10 \mathrm{~mm}$, and an angle of $20^{\circ}$. Since the contours of nonciliated cells were not always discernible, we could not determine the number of adherent bacteria for each type of cell identified in the outgrowth (ciliated, CC; nonciliated, NCC). We used therefore an image analyzer (Bio 500; Biocom, Les Ulis, France) connected to the SEM to draw the outline of the ciliated cell surface and of the microscopic fields, and to determine the area, in square millimeters, of both CC and NCC surfaces (13).

Preliminary assays showed that $P$. aeruginosa adherent to $\mathrm{CC}$ or NCC were often present as aggregates of several bacterial cells. Inasmuch as we could not determine the exact number of bacteria in these aggregates, each one was counted as one bacteria and the pattern of the microorganism distribution in aggregates was systematically specified. This approach underestimates, therefore, the overall adhesion of $P$. aeruginosa.

Time-lapse videomicroscopy of $P$. aeruginosa adherence to epithelial cells. A time-lapse videomicroscopic technique was used to analyze the kinetics of the $P$. aeruginosa adhesion to the respiratory epithelial cells. A CCD camera (Panasonic WV CD 50) connected to the phase contrast inverted microscope (Nikon TMS-F) allowed the recording of the bacterial adhesion phenomenon. The recordings were continuous from time 0 , when the bacterial suspensions were added to the cultures, up to the past $5 \mathrm{~min}$. Then, the images were recorded every $5 \mathrm{~min}$ for a total period of $60 \mathrm{~min}$. At the end of the incubation period, cultures were rinsed with RPMI-Hepes medium at $37^{\circ} \mathrm{C}$ and reobserved. The final magnification on the video monitor was 1,300 .

Evaluation of the self-aggregating tendency of $P$. aeruginosa. Since preliminary results showed the presence of bacterial aggregates adherent to epithelial cells, it seemed necessary to determine whether such aggregates resulted from a self-aggregating tendency of bacterial cells or were induced by secretion products released by epithelial cells. $P_{24}$ was suspended in either RPMI-Hepes medium (control) or in RPMI-Hepes medium previously incubated with cells in culture for $1 \mathrm{~h}$ at $37^{\circ} \mathrm{C}$ (test). Five different 5- $\mu$ l samples of each $P$. aeruginosa suspension were deposited on microscopic glass slides 5, 30, and $60 \mathrm{~min}$ after dispersing the bacterial cells. Slides were fixed, Gram stained, and observed on an optical microscope for detection of bacterial aggregates. To ascertain that the contact with epithelial cells did not induce the synthesis of bacterial compounds that caused bacterial aggregation, the experiment was repeated in the presence of gentamycin at $10 \mu \mathrm{g} / \mathrm{ml}$ to prevent $P$. aeruginosa protein synthesis.

$Q$ uantitation of $P$. aeruginosa aggregation. We used a semiautomatic software to quantify bacterial aggregation. Images of the smears of $P$. aeruginosa in test or control RPMI medium, at 5 and $60 \mathrm{~min}$, were captured with a CCD video camera connected to an optical microscope (Axiophot, Zeiss). The software was run on a PC microcomputer (V286C; Victor Technologies, Rueil-Malmaison, France). A grey level thresholding allowed the isolation of the bacterial images from the background. An isolated bacteria selected on the video screen gave the reference size for further calculation. Then the software searched for the aggregates and calculated their size. Results are displayed in number of bacteria per aggregate and in number of aggregates.

Cytochemical study of sugar residues on epithelial cell surface. In an attempt to identify a relationship between $P$. aeruginosa adhesion and the presence of a specific sugar residue at the epithelial cells surface, we carried out cytochemical studies using different lectins (Table I) conjugated either to $15 \mathrm{~nm}$ colloidal gold (E.Y. Laboratories, Inc., San Mateo, CA) or to FITC (Amersham, Les Ulis, France). For colloidal goldlectin studies, cultures were fixed with $4 \%$ paraformaldehyde in $0.1 \mathrm{M}$ cacodylate buffer $\mathrm{pH} 7.4$, before being incubated with lectin complexes at $35 \mu \mathrm{g} / \mathrm{ml}$ for $1 \mathrm{~h}$ at room temperature. Thereafter, cultures were rinsed with cacodylate buffer containing $0.05 \%$ ruthenium red, postfixed with $\mathrm{O}_{\mathrm{S}} \mathrm{O}_{4}$ at $1 \%$ in cacodylate-ruthenium red buffer for $2 \mathrm{~h}$ at room temperature, embedded in Epon, and examined on TEM.

For FITC-lectin labeling, cultures were fixed in 4\% paraformaldehyde in PBS, rinsed with PBS and PBS-BSA, before being incubated with lectin complexes at $10-20 \mu \mathrm{g} / \mathrm{ml}$ for $1 \mathrm{~h}$ at room temperature. The specificity of the labeling was controlled by using lectin solutions previously incubated with their hapten sugar at $0.2 \mathrm{M}$ concentration for $30 \mathrm{~min}$.

To favor bacterial localization in our fluorescent cytochemical studies, we carried out a double labeling technique: cultures exposed to $P_{10}$ were first labeled with lectin-FITC complexes, as described. Thereafter, cultures with adherent bacteria were incubated with an antiserum against $P$. aeruginosa somatic antigen 0:10 (Institut Pasteur, Paris) diluted 1:10 in PBS-BSA for $1 \mathrm{~h}$ and later with an anti-rabbit IgG conjugated with Texas red (Amersham Corp., Arlington Heights, IL) for $1 \mathrm{~h}$.

Cytochemical fibronectin study. To ascertain whether modulation of the expression of fibronectin (FN) during migration $(15,16)$ and differentiation of epithelial respiratory cells would interfere with the adhesion of $P$. aeruginosa, we searched for FN by using both a double labeling immunofluorescent (IF) and TEM techniques.

For IF, paraformaldehyde-fixed cultures exposed to $P_{10}$ were treated sequentially with goat anti-serum to FN (Sigma Chemical Co., St. Louis, MO) at 1:50 in PBS-BSA for $1 \mathrm{~h}$, with biotin-conjugated anti-goat IgG (Amersham) diluted at 1:25 (1 h), and with the complex streptavidin-FITC at 1:25 (45 min). Labeling of attached bacteria by the IgG-Texas red complex was carried out as described before. In control experiments, we omitted the primary antiserum. Moreover, control cultures that had not been exposed to bacteria were examined 
in parallel. IF specimens were observed on a microscope equipped with epifluorescence illumination (Axiophot Zeiss) and selected areas were analyzed on a confocal laser system (MRC 600; Bio-Rad Laboratories, Richmond, CA) connected to the Axiophot microscope.

For TEM studies, fixed cultures exposed to $P_{24}$ or to $P_{10}$ were incubated for $1 \mathrm{~h}$ with goat antiserum to $\mathrm{FN}$, and later with the complex protein A-colloidal gold. Thereafter, cultures were rinsed, postfixed with $\mathrm{O}_{3} \mathrm{O}_{4}$ at $1 \%$, embedded in Epon, and observed on TEM.

Statistical analyses. Data are expressed as means $\pm \mathrm{SD}$. Differences between means were analyzed by Student's $t$ test.

\section{Results}

\section{Characterization of cell cultures}

Phase contrast microscopy. After 3-4 d of culture, the explants were surrounded by a large area of epithelial outgrowth following cell migration from the explants as well as cell division. In the outgrowth area, both ciliated cells and nonciliated cells were present, the $\mathrm{CC}$ being more frequent in the region nearest the explants. At the periphery of the outgrowth, cells from a lower cell layer (LCL) were often seen protruding beneath the leading edge of migration of the superficial epithelial cells (Fig. $1 \mathrm{~A}$ ). Besides, in some areas, the upper layer of epithelial cells retracted spontaneously allowing the lower cellular stratum to be exposed (Fig. $1 \mathrm{~B}$ ).

Scanning electron microscopy. Neighboring ciliated cells at different steps of differentiation could frequently be observed in a same microscopic field. In our culture model, they differed from CC normally found in the airway epithelium as they presented a central cluster of cilia surrounded by a microvillicovered surface area (Fig. 2). NCC were also covered by microvilli that apparently did not differ from those observed on CC.

Transmission electron microscopy. Low magnification view of vertical sections demonstrates that surface epithelial cells rested upon an underlying continuous stratum composed of at least one cell layer. As cells from the upper layer were more distant from the explant, they became more flattened (not shown). At higher magnification, it was noticed that CC presented microvilli that were longer and thinner than those from NCC, presenting a simple or branching pattern. These microvilli seem to be characteristic of CC insofar as they were identified on differentiated $\mathrm{CC}$ or on $\mathrm{CC}$ in the way of differentiation (not shown).

NCC presented a very heterogeneous morphology that varied from those presenting numerous apical microvilli with a well developed membrane glycocalyx to others presenting only a few random surface microvilli. Some of the NCC could be characterized as secretory cells by the presence of secretory granules, but most of them did not present any particular char-

Table I. Lectin Complexes Used and Their Carbohydrate Residue Specificities

\begin{tabular}{lc}
\hline \multicolumn{1}{c}{ Lectin complexes } & Sugar specificity (14) \\
\hline Con A-colloidal gold and FITC & $\alpha$-D-mannose; $\alpha$-D-glucose \\
WGA-colloidal gold and FITC & $N$-acetylglucosamine; $N$-acetyl \\
& neuraminic acid (sialic acid) \\
PNA-FITC & Galactose $\beta 1-3 N$-acetyl- \\
& galactosamine
\end{tabular}
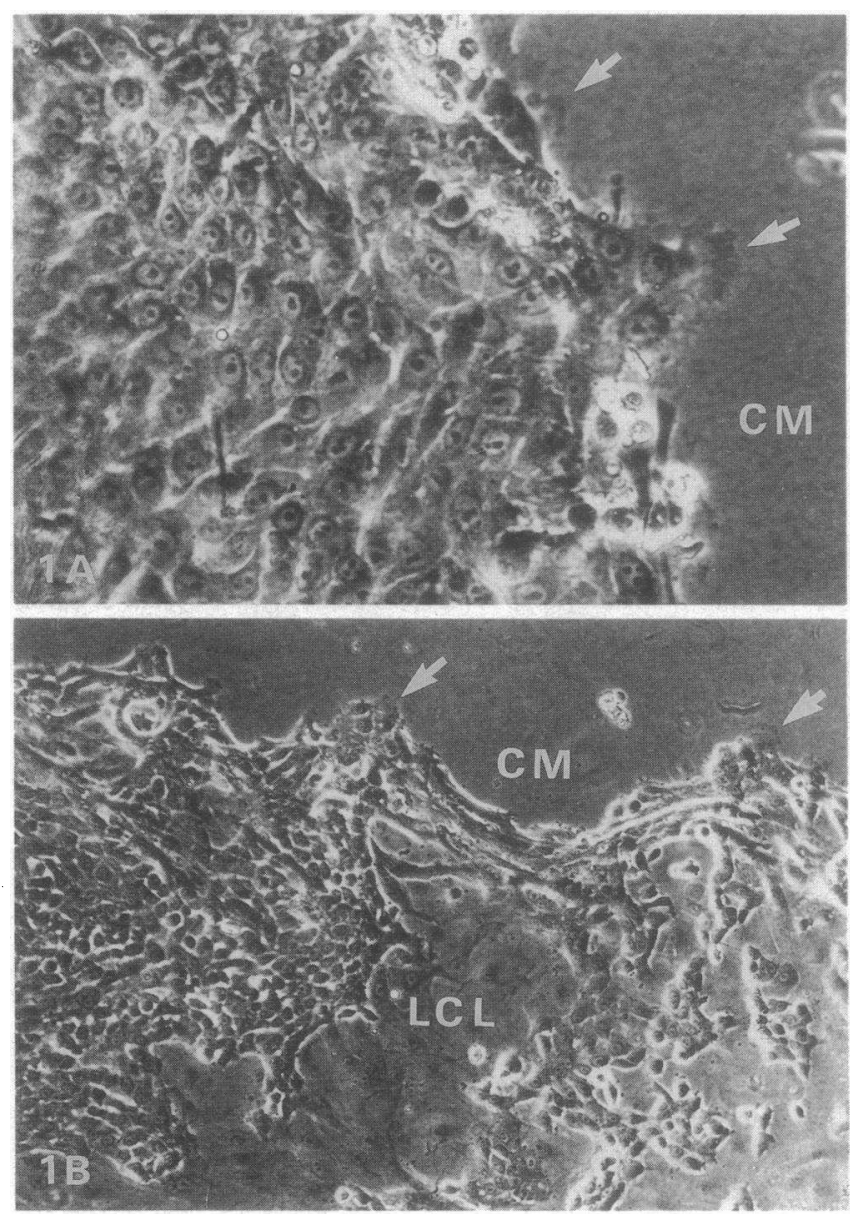

Figure 1. Phase contrast micrographs of epithelial respiratory cells in culture. $(A)$ Note the protrusion of cells from the lower cellular layer beneath the leading edge of migration of the upper cells (arrows). (B) The lower cell layer $(L C L)$ exposed due to retraction of upper cells. Arrows have the same significance as in $A ; C M$, collagen matrix. $\times 830$ and 520 .

acteristic of cell differentiation and were, therefore, classified as undifferentiated cells.

\section{$P$. aeruginosa adherence to epithelial respiratory cells}

By SEM, bacteria were seen attached both to CC and NCC of the upper cell layer, but a striking difference was observed in the distribution pattern of $P$. aeruginosa, as shown in Fig. 3. $\mathrm{P}_{24}$ associated with $C C$ were in $71.3 \pm 15.3 \%$ of the cases present as large aggregates of countless microorganisms (Fig. $4 A$ ), while the percentage of aggregated bacteria associated with NCC were of $19.0 \pm 14.0 \%(P<0.001)$. For $P_{10}$, the percentage of aggregated bacteria associated with $\mathrm{CC}$ was also significantly higher than the percentage associated with NCC $(70.8 \pm 18.0$ and $10.3 \pm 6.5 \%$, respectively; $P<0.001$ ). Both $P_{24}$ and $P_{10}$ were seen to adhere avidly to type I collagen matrix, in most cases as nonaggregated bacteria (Fig. 4 B). As shown in Fig. 5, the number of microorganisms associated with $C C$ surface was significantly higher than that associated with $\mathrm{NCC}$ surfaces $(9.8 \pm 5.3$ and $1.7 \pm 0.7 \times 10^{-4}$ bacteria $/ \mu \mathrm{m}^{2}$ for $P_{24}$, respectively; $P<$ 0.001 ) and $19.0 \pm 11.4$ and $7.2 \pm 4.6 \times 10^{-4}$ bacteria $/ \mu \mathrm{m}^{2}$ for $P_{10}$ $(P<0.02)$. The percentage of $C C$ presenting attached bacteria was, for $P_{24}$ and $P_{10}$, of $28.6 \pm 5.7$ and $24.0 \pm 9.0 \%$, respectively. 


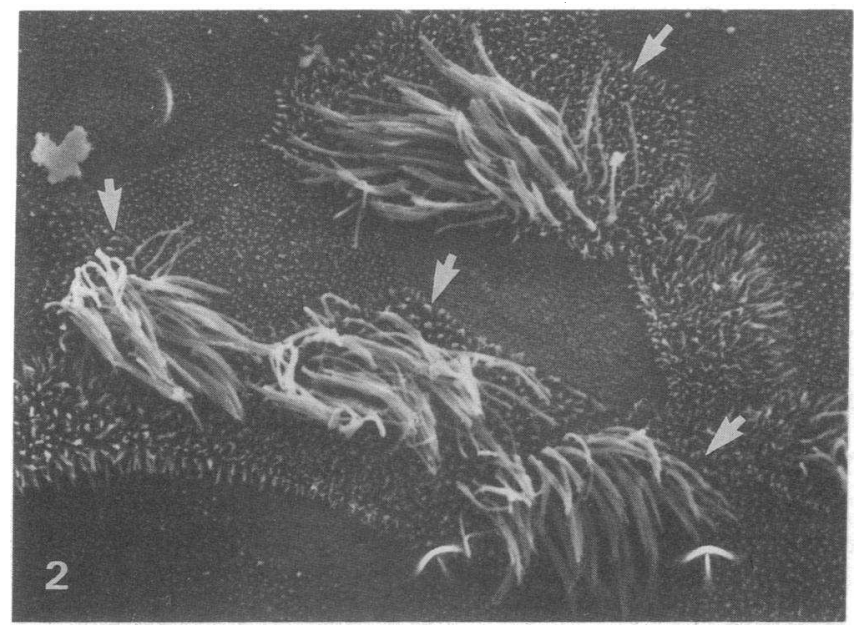

Figure 2. Scanning electron micrograph of epithelial respiratory cell culture showing ciliated (arrows) and nonciliated cells found in the outgrowth area around the explant. $\times 3,600$.

If we consider only $\mathrm{CC}$ with nonagglutinated attached bacteria, the percentages were $11.9 \pm 8.8$ and $5.5 \pm 4.4 \%$, respectively.

An exciting SEM finding was the $P$. aeruginos $a$ adhesion to cells of the LCL, which were identified both at the leading edge of migration of the outgrowth and in areas where the upper cells retracted spontaneously allowing the LCL to be exposed (Fig. 6). As shown in Fig. 5, the number of $P_{24}$ associated with the LCL $\left(34.1 \pm 17.1 \times 10^{-4}\right.$ bacteria $\left./ \mu \mathrm{m}^{2}\right)$ was significantly higher $(P<0.001)$ than that of bacteria associated with $C C$ or NCC surfaces. In $82.6 \pm 5.1 \%$ of the cases, $P_{24}$ attached to the LCL were present as aggregates of numerous microorganisms. The adhesion of $P_{10}$ to cells of the LCL was not quantified, but was similar to $\mathrm{P}_{24}$ adhesion, as observed in SEM and videomicroscopic studies.

To ascertain that $P$. aeruginos $a$ aggregates have not simply settled by gravity on the LCL, two cultures on collagen-coated coverslips were incubated inverted in $P_{24}$ suspension, as described by Spurr-Michaud et al. (17). Although the quantitation of bacterial adhesion was not performed, numerous bacterial aggregates were seen attached at the periphery of the outgrowth as well as to the tips of cilia (not shown). The preservation of the distribution pattern of bacteria on the outgrowth of respiratory cells demonstrates that the results are not a culture artifact.

By TEM, $P$. aeruginosa were never seen attached along cilia or at the interciliary spaces, but were identified trapped at the

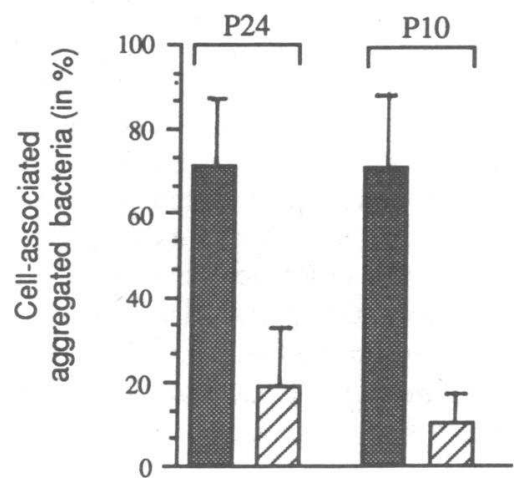

Figure 3. Percentage of aggregated $P$. aeruginos $a$ adherent to ciliated $(C C)$ and to nonciliated $(N C C)$ cell surfaces. E. CC; $₫$, NCC.
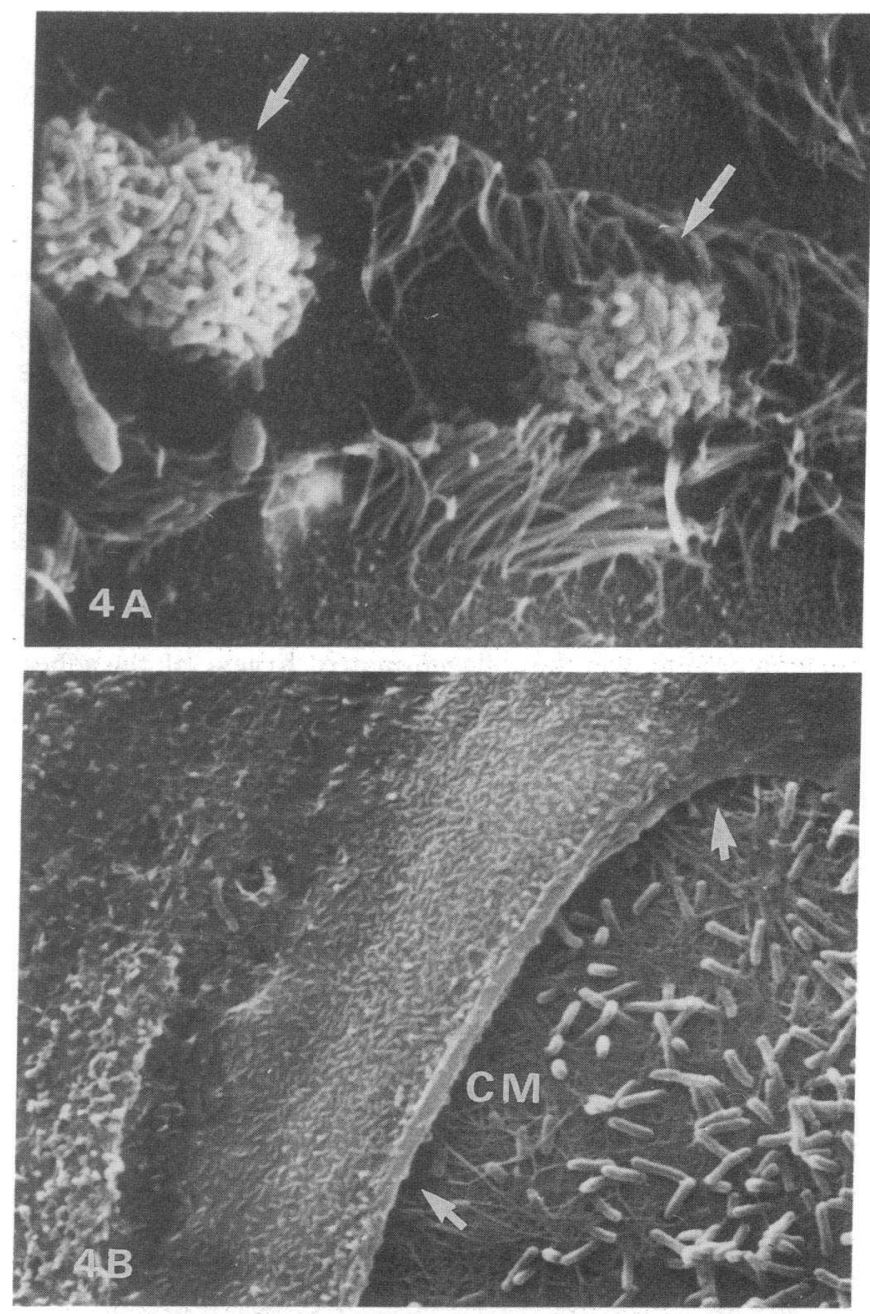

Figure 4. Scanning electron micrographs of respiratory cell culture showing $(A)$ large aggregates of countless $P$. aeruginosa associated with ciliated cells (arrows); $(B)$ nonaggregated bacteria adhering to the type I collagen matrix $(C M)$. Arrows, periphery of the outgrowth. $\times 5,500$.

extremities of cilia, as aggregates (Fig. $7 \mathrm{~A}$ ). A matrix-like material was always seen surrounding aggregated bacteria (Fig. 7, $A$ and $B$ ). The interaction of aggregated bacteria with cilia appeared to occur by means of this matrix (Fig. $7 \mathrm{~A}$ ). In contrast, bacteria were seen attached directly to NCC or to the collagen matrix, usually as nonaggregated cells (not shown). No surrounding matrix-like material was seen in nonaggregated $P$. aeruginosa.

\section{Time-lapse videomicroscopy}

The dynamic adhesion of $P$. aeruginosa in suspension to the epithelial respiratory cells was analyzed by time-lapse videomicroscopy. Immediately after the addition of the bacterial suspension to the cell culture, well individualized $P$. aeruginosa were seen to be propulsed by the ciliary activity. As early as 5 min after the beginning of the incubation period, small aggregates of bacteria were seen to appear in the culture medium. These aggregates, which increased progressively in number and size, were also initially swept out by cilia beating, but became progressively trapped at the extremities of cilia that continued to beat with trapped bacterial aggregates. P. aeruginosa adher- 


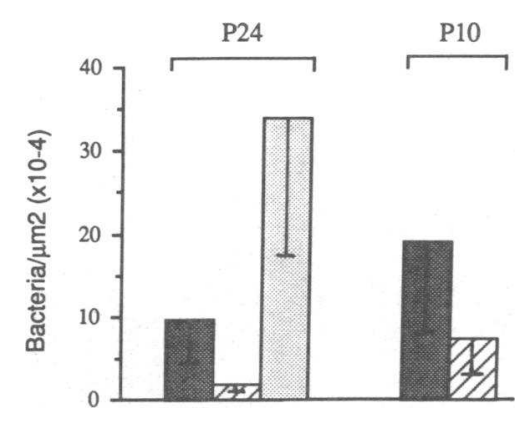

Figure 5. Mean adherence of $P$. aeruginosa to ciliated, nonciliated, and lower cellular layer surfaces. 1 , CC surface; , NCC surface; $;$, LCL surface.

ence to the exposed lower cellular stratum was a latter phenomenon. In contrast, $P$. aeruginosa adherence to the collagen gel was a very early phenomenon occurring within the first $5 \mathrm{~min}$, even before the aggregation of bacteria occurred. Such almost instantaneous adherence explains the nonaggregated pattern of bacteria present over the collagen-matrix. In general, the adhesion of $P$. aeruginosa to the cell cultures was completed within a 30-min period. The observation of the cultures after rinsing
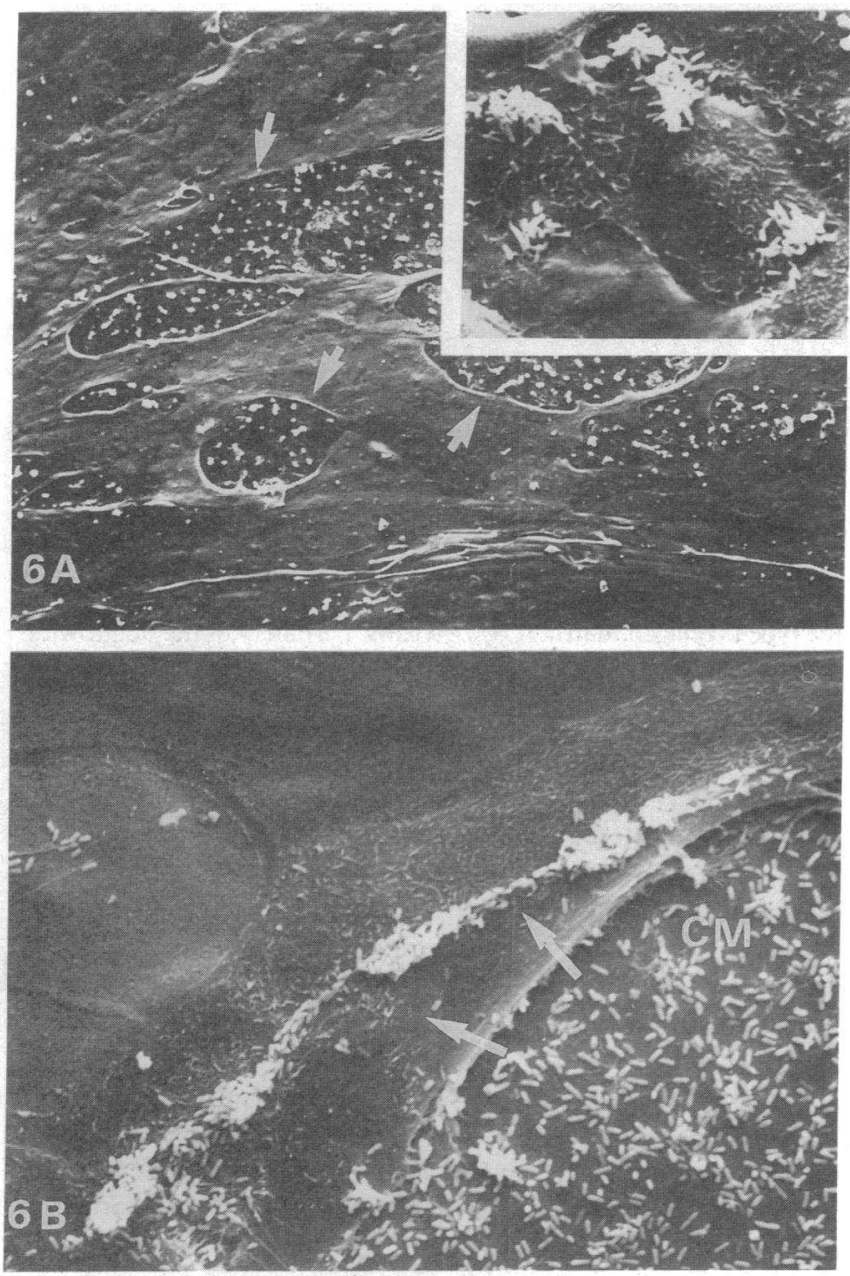

Figure 6. Scanning electron micrographs showing the lower cell layer with many adherent bacteria. $(A)$ LCL (arrows) is exposed due to retraction of upper cells. The inset shows aggregated bacteria adherent to the LCL at a higher magnification; $(B) L C L$ exposed at the periphery of the outgrowth (arrows) with adherent aggregated or nonaggregated bacteria. Note the presence of numerous bacteria adherent to the collagen matrix gel $(C M) . \times 215,2,325$, and 2,325 .
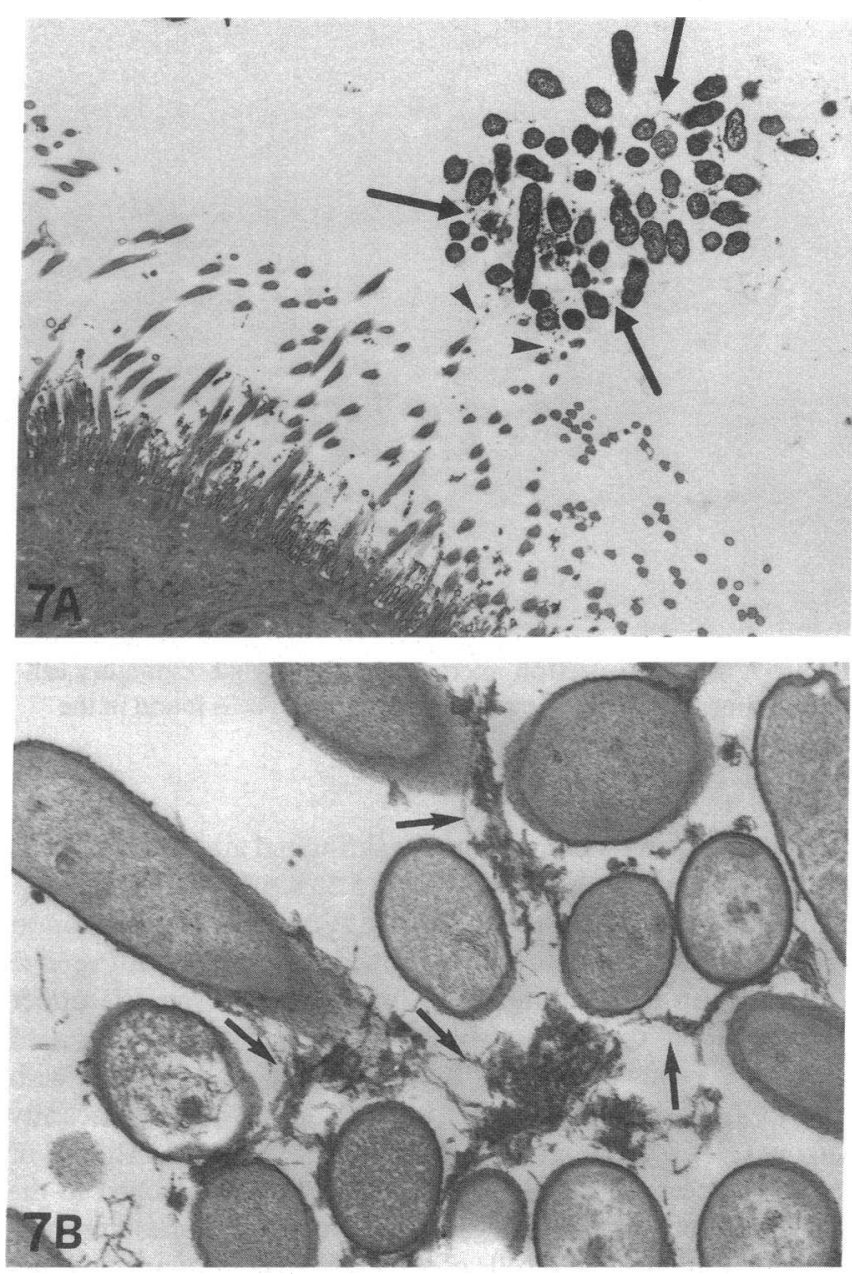

Figure 7. Transmission electron micrographs of $P$. aeruginosa aggregates $(A)$ trapped at the extremities of cilia. Note the presence of a matrix-like material surrounding bacteria (arrows). Arrowheads correspond to the matrix surrounding material in close proximity to cilia. (B) Higher magnification of aggregated $P$. aeruginosa surrounded by a matrix-like material (arrows). $\times 4,000$ and 23,000 .

showed that most of the bacterial aggregates trapped at the extremities of cilia have been eliminated while the pattern of $P$. aeruginosa adhesion to the cells of the LCL or to the collagen matrix was not modified.

Evaluation of the self-aggregating tendency of $P$. aeruginosa To ascertain that the appearance of bacterial aggregates was not the result of a self-aggregating tendency of $P$. aeruginosa, $\mathrm{P}_{24}$ suspensions prepared in control or in test RPMI-Hepes medium were observed. As early as $5 \mathrm{~min}$ after the preparation of each $P$. aeruginosa suspension, there was already a distinct pattern of bacterial cell distribution on glass slide smears: bacteria incubated with control medium were present as isolated cells well distributed over the smear, while bacteria in contact with medium previously incubated with cell cultures exhibited an aggregating tendency (Fig. 8). The difference between them was more striking after a $1-\mathrm{h}$ incubation period. The quantitation of $P$. aeruginosa aggregation showed that $0.9 \pm 0.2 \%$ of the aggregates present on test suspension, as early as at $5 \mathrm{~min}$, contained $>500$ bacteria. No such aggregates were seen on control suspension. 


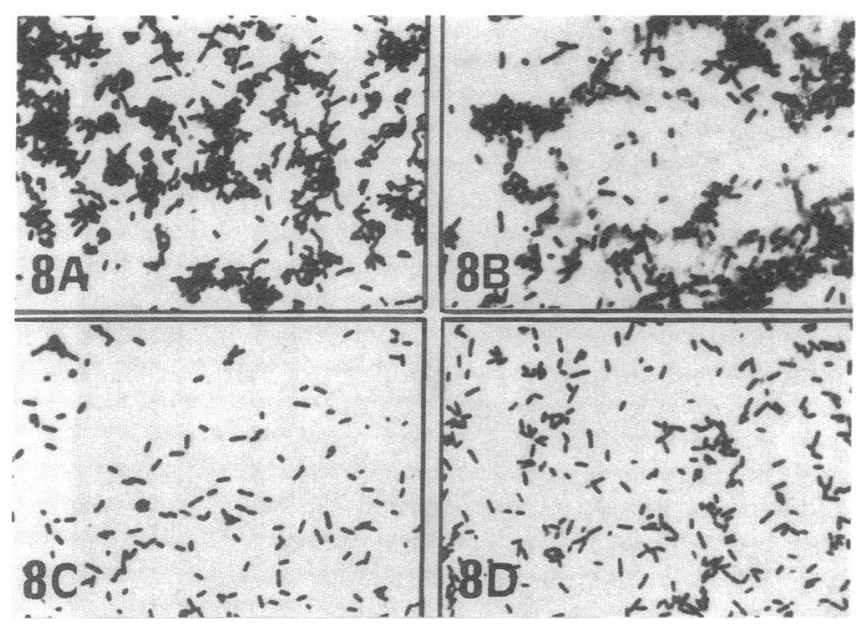

Figure 8. Photomicrographs of smears prepared from $P$. aeruginosa suspensions in control $(C$ and $D$ ) and in test $(A$ and $B)$ RPMI-Hepes medium; $5(A$ and $C)$ and $60(B$ and $D)$ min after the preparation of each bacterial suspension.

A significant difference was noted between the size of the greatest $\mathbf{P}_{24}$ aggregate present in control and test suspensions at 5 min (146.5 \pm 192.7 and $1,839.4 \pm 1,068.3$ bacteria, respectively) and at $60 \mathrm{~min}(410.8 \pm 339.7$ and $2,740.4 \pm 369.9$ bacteria, $P<0.001)$. Although quantitative study was not performed, no difference was noted when test or control $P$. aeruginosa suspensions were prepared in the presence of gentamycin.

\section{Cytochemical studies}

The microscopic observation of cultures labeled by the wheat germ agglutinin (WGA)-FITC complex showed cells from the upper cell layer to differ in the labeling pattern: well labeled cells were seen neighboring poorly labeled cells (not shown). Cells of the lower cellular stratum, more easily identified at the edge of the outgrowth area, were shown to fluoresce less intensely than the adjacent upper cells. Moreover, a diffuse pattern of fluorescence was noted, in contrast to that of upper cells where the microvilli were markedly labeled. No relationship could be established between the presence of adherent bacteria and WGA-FITC staining.

Ciliated cells were never labeled by the WGA-gold complex. In contrast, WGA-gold binding to NCC was shown to increase with cell differentiation, as evaluated by the development of apical microvilli both in number and in length and by the development of the plasma membrane glycocalyx (Fig. 9, $A$ and $B$ ). However, $P$. aeruginosa adhesion to NCC could not be directly and exclusively attributed to the presence of WGAbinding sites on epithelial cells, inasmuch as bacteria adhered either to cells presenting a well developed and well labeled glycocalyx (Fig. $9 \mathrm{D}$ ) or to poorly differentiated and poorly labeled cells (Fig. $9 C$ ).

No relationship could be established between Con A labeling and cell differentiation as either $\mathrm{CC}$ or NCC from the upper cellular layer were labeled by the Con A-gold complex. However, the analysis of cultures labeled by the Con A-FITC complex showed that cells of the periphery of the outgrowth were intensely labeled, in contrast to the upper cells which were either negative or poorly fluorescent (Fig. $10 \mathrm{~A}$ ). No difference could be noticed between the percentage of fluorescent cells of the periphery of the outgrowth presenting attached bacteria and of cells without bacteria.

As a whole, cells from the upper cellular stratum fluoresced dimly when labeled by the arachis hypogea agglutinin (PNA)FITC complex. In contrast, cells from the edge of the outgrowth were shown to be intensely labeled by the PNA-FITC complex (Fig. $10 \mathrm{~B}$ ). The percentage of PNA-labeled cells presenting adherent bacteria, revealed by the labeling with the anti-Ig-Texas red complex, was significantly higher $(P<0.02)$ than that without bacteria (69.8 and $30.1 \pm 5.7 \%)$.

\section{Fibronectin studies}

Although some nonfluorescent cells were observed, as a whole epithelial respiratory cells in culture were dimly fluorescent after exposure to the anti-FN serum followed by the streptavidin FITC complex (Fig. $11 \mathrm{~A}$ ). However, a few intensely FN-labeled cells were identified, both at the periphery of the culture and in central areas of the outgrowth (not shown). Besides this fine labeling pattern of insoluble cell-associated FN, an intensely fluorescent fibrillar material was seen over the epithelial cell surfaces (Fig. 11, $B$ and $C$ ) and the collagen matrix (not shown), both in $P$. aeruginosa-exposed and in control cultures not exposed to bacteria. This FN-containing fibrillar material was seen to be closely associated with aggregated bacteria adherent to $\mathrm{CC}, \mathrm{NCC}$, or to the collagen matrix. The culture observation on the confocal microscope allowed a better understanding of the interaction between fibrillar FN and $P$. aeruginosa (Fig. 11, C-E). The presence of the FN-containing fibrillar material was confirmed by TEM studies as well as its association with aggregated bacteria (Fig. 12). No relationship could be established between low amounts of insoluble FN at respiratory cell surface and the adhesion of $P$. aeruginosa.

\section{Discussion}

The specific mechanisms of the colonization of cystic fibrosis patient airways by $P$. aeruginosa remain unclear. In vitro studies have shown $P$. aeruginosa to adhere to cilia from human tracheal cells in suspension (18), but they never infect tracheobronchial mucosa of healthy individuals. Moreover, $P$. aeruginosa interaction with intact epithelium was never noted in lungs from cystic fibrosis patients (2), neither was bacteria entanglement within cilia. In contrast to sites with intact epithelium, where bacteria remained intraluminal, $P$. aeruginosa were seen attached to denuded membranes or to inflamed surfaces of the injured epithelium. These discrepancies among clinical, anatomopathological, and in vitro data probably reflect the lack of an adequate in vitro model for studying the mechanisms controlling $P$. aeruginosa infection of the respiratory epithelium.

Studies on normal human tracheobronchial tissue are difficult to perform because excised specimens are rarely available. Therefore, in this study, we worked on nasal polyp explant outgrowth primary culture as a model of tracheobronchial epithelium. The outgrowth cultures provide a good model for studying bacterial adhesion to epithelial respiratory cells at different steps of differentiation.

In our study, $P$. aeruginosa adhesion to $\mathrm{CC}$ was nonuniform and, in most cases, $P$. aeruginosa were present as aggregates trapped at the extremities of cilia, which suggests that a non-receptor mechanism of adherence may have operated. 

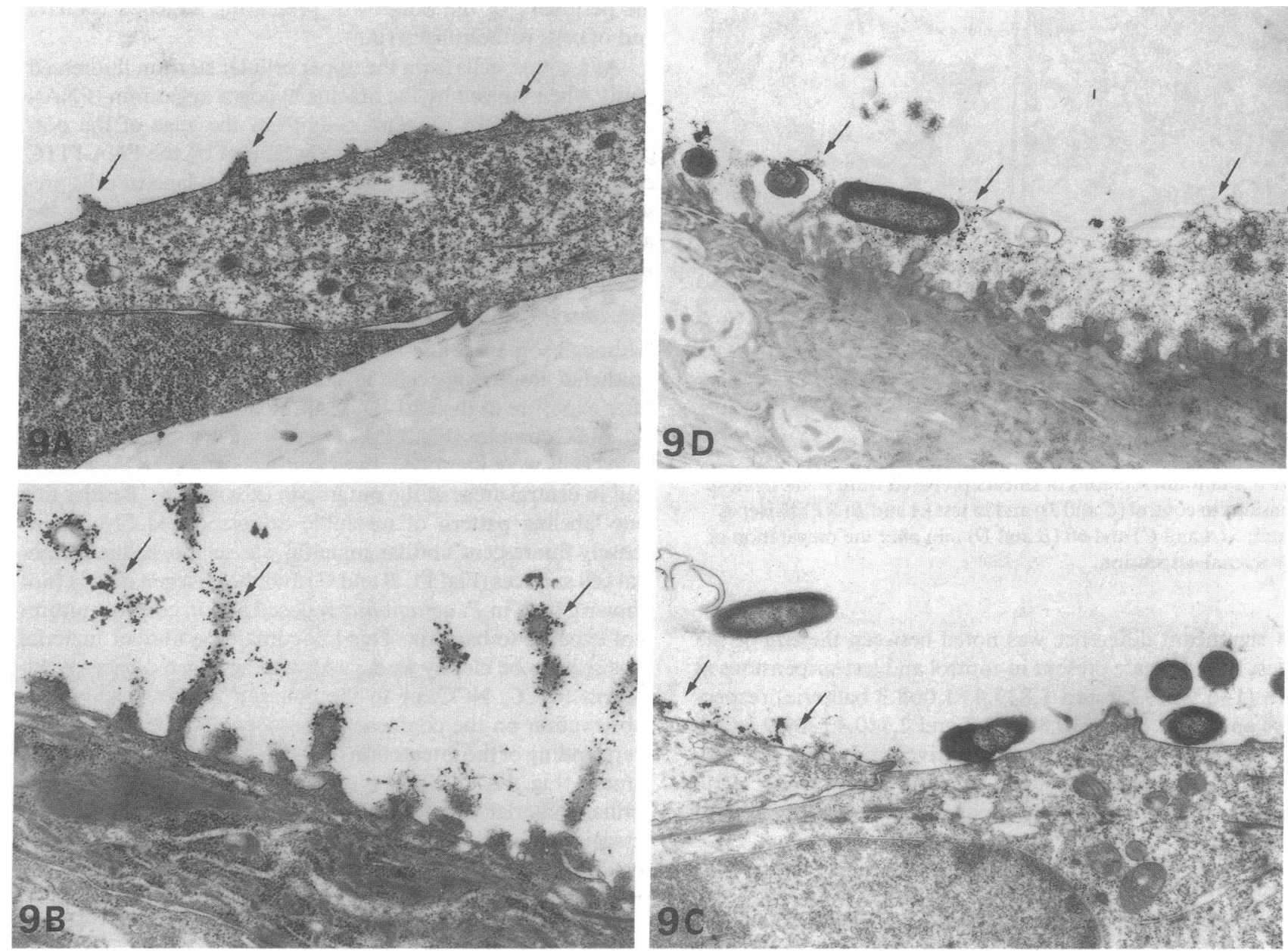

Figure 9. Transmission electron micrographs of respiratory cells labeled by the WGA-colloidal gold complex showing $(A)$ poorly differentiated nonciliated cells with rare colloidal gold granules attached to the plasma membrane (arrows); $(B)$ NCC presenting long and numerous microvilli with a well developed glycocalyx well labeled by the WGA gold complex (arrows); $(C) P$. aeruginosa adhering to a poorly differentiated and nonlabeled NCC. Note adjacent labeled NCC (arrow); (D) P. aeruginosa adhering to a NCC presenting a highly developed glycocalyx, well labeled by the lectin complex. $\times 14,000,18,000,12,000$, and 12,000 .

The percentage of CC presenting nonaggregated attached microorganisms was at least twice lower than that with aggregated attached $P$. aeruginosa. The comparison of our results with those of others is difficult due to major differences in the methodological approaches. However, our mean index of attached microorganisms per $\mathrm{CC}$ is much lower than those reported by Franklin et al. (18) or Niederman et al. (19) working on human tracheal cells in suspension. Accordingly, in agreement with Baker and Marcus (20) and with Marcus et al. (21), we conclude that the nonmucoid $P$. aeruginosa variant adheres only poorly, if at all, to the undamaged ciliated epithelium.

Aggregated $P$. aeruginosa were shown to be surrounded by a matrix-like material. At least three types of evidence suggest that such aggregates resulted from the bacterial aggregation due to some factors released in the culture medium: $(a)$ by videomicroscopy, bacteria were seen to be progressively aggregated after the addition to the cell cultures; $(b)$ bacteria, which were almost immediately trapped by the collagen matrix, were present as nonaggregated cells; and (c) bacterial suspensions prepared in epithelial cell cultures-conditioned RPMI medium were shown to aggregate while those prepared with control RPMI medium did not.
Epithelial respiratory cells in culture have been shown to synthesize glycoconjugates and to release them spontaneously into the culture medium $(22,23)$. Preliminary results from our laboratory suggest that mucin may be involved in the observed $P$. aeruginosa aggregation, as shown by ongoing immunocytochemical studies using a monoclonal antibody $17 \mathrm{~B}_{1}$ developed using purified large molecular weight macromolecules of rhesus monkey tracheal secretion as immunogen $(24,25)$, kindly supplied by Dr. R. Wu (California Primate Research Center, University of California). Mucin-like glycoproteins present in saliva are known to induce the aggregation of oral bacteria (26, 27). Bacterial aggregation in the respiratory tract may be of great in vivo significance since large aggregates are supposed to be cleared more easily by the mucociliary transport than individual organisms.

At the periphery of the outgrowth culture, cells do not make contact with opposing cells and continue to migrate $(28,29)$. Because they behave like cells close to wound edges, which in response to focal loss of an adjacent cell spread and migrate to cover denuded areas $(30,31)$, the outgrowth culture can be considered as a model of wounded epithelia.

The recruitment of components of internal membranes 

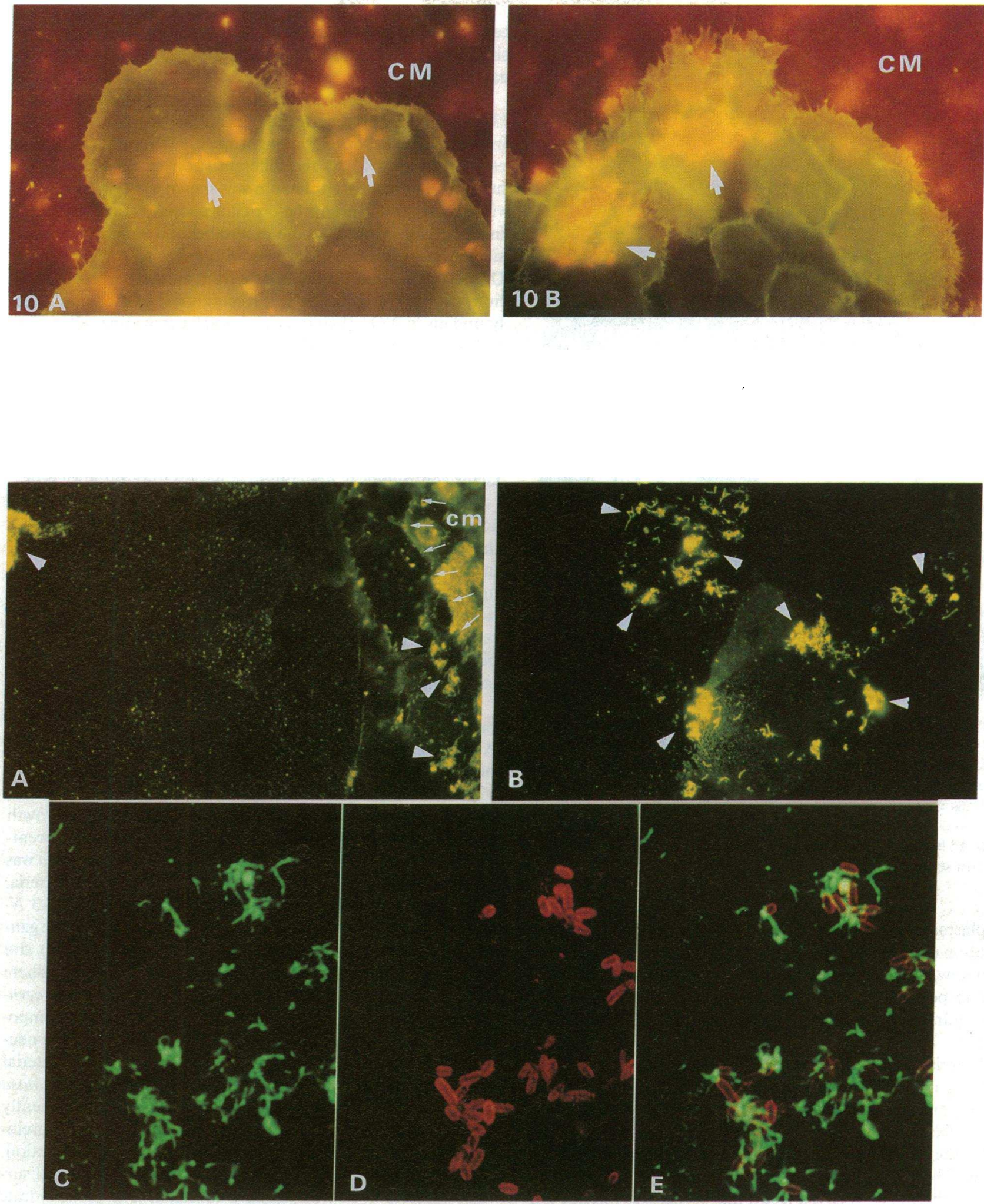

Figure 10. Photomicrographs of the periphery of the outgrowth showing cells labeled by the Con A-FITC $(A)$ and by the PNA-FITC complex $(B)$ with many attached aggregated or nonaggregated bacteria (arrows) labeled by the Texas red complex. The background staining in red is due to the labeling of collagen matrix $(C M)$-attached bacteria by the Texas red complex.

Figure 11. Distribution of fibronectin in epithelial respiratory cells in culture as detected by indirect immunofluorescence. $(A)$ The border of the outgrowth is indicated by arrows. Note the dim labeling of the epithelial cells in contrast with the collagen matrix $(\mathrm{cm})$ intensely fluorescent. A fibrillar fluorescent material is seen over the epithelial surface (arrowheads). (B) Epithelial cells FN-labeled neighboring nonlabeled cells. Note the presence of a fibrillar fluorescent material that lies over FN-labeled or nonlabeled epithelial cells (arrowheads). (C) Higher magnification of the FITC labeled fibrillar FN. $(D)$ Texas red-labeled bacteria associated with fibrillar FN. $(E)$ Computer reconstruction of the association of Texas red-labeled $P$. aeruginosa $(D)$, with FITC-labeled fibrillar FN $(C)$, as observed in confocal laser microscopy. $A$ and $B, \times 830 ; C-E, \times 1,800$. 


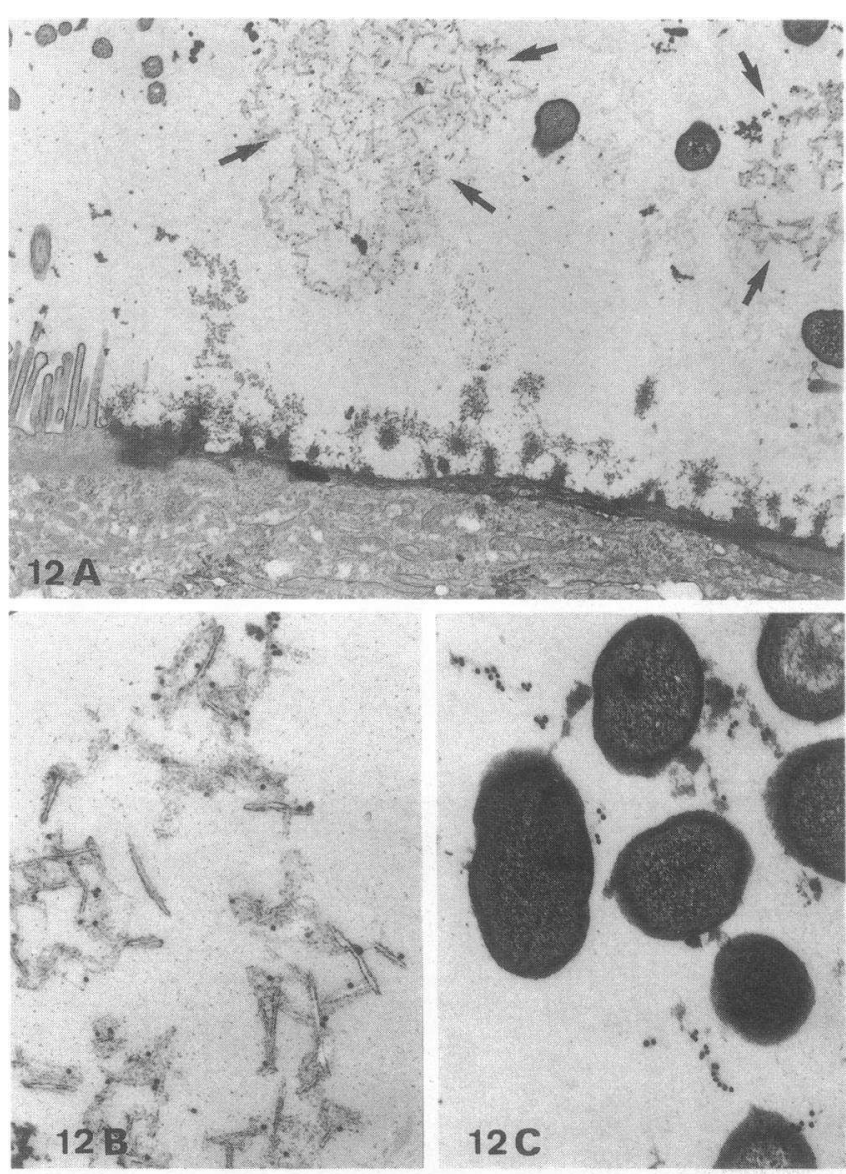

Figure 12. Transmission electron micrographs of the epithelial respiratory cells exposed to the antifibronectin serum and to the protein A-colloidal gold complex. $(A)$ Note the presence of a fibrillar material well labeled (arrows) lying over the epithelial surface. (B) Higher magnification of the fibronectin-containing fibrillar material labeled by colloidal gold granules. $(C)$ Labeling of the matrix surrounding aggregated bacteria adherent to the respiratory cells by the antifibronectin serum. $\times 12,000,24,500$, and 22,500 .

into plasmalemma, which occurs during cellular spreading and migration (32), as well as a change in the relative rates of membrane flow, processing reactions and glycosyl transfer are likely to be responsible for the described alteration of cell surface carbohydrates during cell migration $(7,8)$ and differentiation (6)

Bacterial adhesion to host cells has been shown to depend on direct molecular interaction between microbial structures and host glycoconjugate receptors from the plasma membrane glycocalyx. Several studies have shown that sialic acid residues inhibit the adhesion of nonmucoid $P$. aeruginosa to different tissues (33-36).

The binding of WGA, a lectin that recognizes interior and terminal $\mathrm{N}$-acetylglucosamine, as well as terminal sialic acid residues (14), to adult mouse corneal epithelium was shown to decrease with cell maturation (37). Other studies similarly have shown that immature cells possess many sialic acid residues, whereas aging reduces their number (38). WGA binding to cells migrating to repair an epithelial injury was also shown to be much greater than binding to stationary cells (7). Accordingly, we hypothesized that $P$. aeruginosa adhesion to injured epithelium would be favored by the usual events of wound repair, i.e., cell migration and proliferation, which would explain the persistent respiratory infection in patients with chronic lung diseases.

In contrast to data obtained with mouse corneal epithelium (37), the WGA binding to human epithelial respiratory cells increased with the development of apical surface microvilli and cellular glycocalyx. As the differentiation of ciliated cells in human fetal tracheal epithelium was shown to begin by microvillogenesis, which occurs before ciliogenesis (39), cells presenting increased microvilli, both in number and length, were considered more mature than cells with fewer apical microvilli. Our results also contrast with data from animal corneal epithelium studies (7), since the apical membrane of the upper cells bound more WGA than migrating and/or spreading cells of the periphery of the outgrowth.

In our study, $P$. aeruginosa were shown to adhere to NCC presenting either well developed and well WGA-labeled microvilli or a poorly developed and poorly labeled glycocalyx. Therefore, the presence of the sugar residues revealed by the cell reactivity with the WGA complex does not seem to be the only factor controlling $P$. aeruginos $a$ adhesion to respiratory cells.

The most interesting finding of our study was $P$. aeruginos $a$ adhesion to the cells of the lower cell layer protruding beneath the leading edge of migration of the outgrowth. A similar finding was reported by Spurr-Michaud et al. (17), studying $P$. aeruginosa adhesion to healing rat corneas. $P$. aeruginosa adhesion to both migrating cells and basal lamina was significantly reduced by preincubation with Con $\mathrm{A}$, which suggested a possible receptor role for mannose residues in $P$. aeruginos $a$ adhesion to injured corneas.

In our study, the cells of the periphery of the outgrowth presenting attached bacteria were intensely labeled by the Con A-FITC complex. The preferential binding of Con A complexes to migrating cells has already been described in other in vitro models of repairing tissues $(7,8)$.

The cells of the leading edge of migration of the outgrowth were also labeled differently by the lectin PNA and the percentage of PNA-labeled cells presenting attached $P$. aeruginosa was higher than the percentage of labeled cells without bacteria. The specificity of PNA is the disaccharide galactose $\beta 1-3 N$ acetylgalactosamine, which is the terminal sequence of the ganglioside asialo $\mathrm{Gm}_{1}$. Studies from Krivan et al. $(40,41)$ and Baker and Svanborg-Eden (42) showed $P$. aeruginosa to adhere to asialo $\mathrm{Gm}_{1}$. Recently, Panjwani et al. (43) reported $P$. aeruginosa to adhere to different neutral glycosphingolipid components of both stationary and migrating cells. Among these neutral glycosphingolipids, asialo $\mathrm{Gm}_{1}$ showed an intense bacterial binding. Finally, Singh et al. (44) showed that the $P$. aeruginosa adhesion to scarified adult mouse corneas could be transiently decreased by premixing bacteria with asialo $\mathrm{Gm}_{1}$ or by preincubating corneas with monosialo $\mathrm{Gm}_{1}$ or with lipase solution. All these studies point to a role of gangliosides as the cell surface receptor for $P$. aeruginosa adhesion. The carbohydrate sequence of neutral glycosphingolipids, supposed to allow the adhesion of $P$. aeruginosa, is not the terminal saccharide recognized by PNA (40-42). Accordingly, it is conceivable that the relationship observed in our study between cell-PNA labeling and presence of attached bacteria represents just indirect evidence of the presence of the membrane glycoconjugate to which $P$. aeruginosa have adhered.

The adhesion of $P$. aeruginosa to buccal epithelial cells has been shown to be inversely proportional to levels of insoluble 
FN on the epithelial cell surface (45-47). In our study, no clear relationship could be established between the presence of cell surface FN and the adhesion of $P$. aeruginosa. In contrast, FN containing fibrillar material was seen to be associated with aggregated $P$. aeruginosa attached to epithelial cells or to the collagen matrix. Similar fibrillar aggregates of FN have been shown to be scattered over the surface of extracellular matrix produced by bovine corneal endothelial cells in vitro (48).

Human epithelial respiratory cells in culture secrete FN into the culture medium (49) and soluble FN in culture medium has been shown to be in equilibrium with FN associated to cell surfaces (50). Incorporation of soluble FN into cell surfaces or extracellular matrix results in the transformation of a dimeric protein into an insoluble fibrous protein in which multimeric fibrils are covalently cross-linked (51). This conformational change is supposed to either uncover or block potential receptor sites for pathogens. Accordingly, Streptococcus sanguis and Borrelia burgdorferi were shown to bind preferentially to insoluble FN $(52,53)$. It is conceivable, therefore, that in our culture model, as reported by Woods et al. $(45,46)$ and Abraham et al. (47), insoluble FN at the epithelial respiratory cell surfaces may serve as a barrier to the adhesion of $P$. aeruginosa while soluble FN would bind to bacteria leading to their aggregation. On the other hand, FN is known to present binding sites for different glycoconjugates such as glycosaminoglycans, mucins, cell surface proteoglycans, and membrane-associated gangliosides $(54,55)$. Insofar as in our preliminary assays the matrix-like material surrounding aggregated $P$. aeruginosa was shown to react with an antimucin antibody, we speculate that bacteria were first aggregated by mucin-like products from the epithelial cells and later on by soluble FN attached to the bacteria-associated mucin. As we have shown a preferential binding of $P$. aeruginosa, both as isolated and as aggregated bacteria, to the PNA-reactive migrating cells of the LCL at the periphery of the culture, it is conceivable that these cells present surface receptors for $\mathrm{FN}$ associated with bacteria. It is exciting that data from Kleinman et al. (56) and Thompson et al. (57) suggest that FN binds to the oligosaccharide part of various membrane-associated gangliosides.

The interaction of $P$. aeruginos $a$ with epithelial respiratory cells seems to be a very complex phenomenon. Based on our results, we speculate that changes of cell surface glycoconjugates related with cell migrating and/or spreading to repair epithelial injury may favor $P$. aeruginos $a$ adhesion and, therefore, be partly responsible for the persistence of infection in patients with chronic lung diseases.

\section{Acknowledgments}

The authors thank Dr. Klossek for providing nasal polyps for this study, C. Fuchey and J. Hinnrasky for their excellent technical assistance, Dr. M. Matsuguchi (Bio-Rad) for his helpful assistance, E. Lamiot for his collaboration in the videomicroscopic quantitative image analysis, D. Ploton for his helpful comments, and C. Champion for typing the manuscript.

This work was carried out at Institut National de la Santé et de la Recherche Médicale (INSERM) Unit 314 Reims, thanks to a collaboration research program supported by grants from INSERM-SYNTHELABO, Association Française de Lutte contre la Mucovisciolose (AFLM), France, and Coordenaçâo de Aperfeiçoamento de Pessoal de Nivel Superior (CAPES), Brazil. G. Colliot was a recipient of a BIOCOM Convention Industrielle de Formation par la Recherche
(CIFRE) grant from Ministére de la Recherche et de la Technologie (MRT).

\section{References}

1. Bodey, G. P., R. Bolivar, V. Fainstein, and L. Jadeja. 1983. Infections caused by Pseudomonas aeruginosa. Rev. Infect. Dis. 5:279-313.

2. Baltimore, R. S., C. D. C. Chrisite, and G. J. W. Smith. 1989. Immunohistopathologic localization of Pseudomonas aeruginosa in lungs from patients with cystic fibrosis. Am. Rev. Respir. Dis. 140:1650-1661.

3. Plotkowski, M. C., G. Beck, J. M. Tournier, M. Bernardo-Filho, E. A. Marques, and E. Puchelle. 1989. Adherence of Pseudomonas aeruginosa to respiratory epithelium and the effect of leucocyte elastase. J. Med. Microbiol. 30:285293.

4. McDowell, E. M., P. J. Becci, W. Schürch, and B. F. Trump. 1979. The respiratory epithelium. VI. Epidermoid metaplasia of hamster tracheal epithelium during regeneration following mechanical injury. J. Nat. Cancer Inst. (Bethesda). 62:995-1008.

5. Chailley, B., E. Boisvieux-Ulrich, and D. Sandoz. 1982. Ciliary membrane events during ciliogenesis of the quail oviduct. Biol. Cell. 46:51-64.

6. Mann, P. L., I. Lopez-Colberg, and R. O. Kelly. 1987. Cell surface oligosaccharide modulation during differentiation. I. Modulation of lectin binding Mech. Ageing Dev. 38:207-217.

7. Gipson, I. K., C. V. Riddle, T. C. Kiorpes, and S. J. Spurr. 1983. Lectin binding to cell surfaces: comparison between normal and migrating corneal epithelium. Dev. Biol. 96:337-345.

8. Ball, R. Y., R. W. Stoddart, C. J. P. Jones, and M. J. Mitchinson. 1989. Saccharide expression on wounded endothelial cell monolayers in vitro. $J$. Cell Sci. 93:163-172.

9. Sharon, N. 1987. Bacterial lectins, cell-cell recognition and infectious disease. FEBS (Fed. Eur. Biochem. Soc.) Lett. 217:145-157.

10. Plotkowski, M. C., E. Puchelle, G. Beck, J. Jacquot, and C. Hannoun. 1986. Adherence of type I Streptococcus pneumoniae to tracheal epithelium of mice infected with influenza A/PR8 virus. Am. Rev. Respir. Dis. 134:1040-1044.

11. McDowell, E., T. Ben, C. Newkirk, S. Chang and L. M. De Luca. 1987. Differentiation of tracheal mucociliary epithelium in primary cell culture recapitulates normal fetal development and regeneration following injury in hamsters. Am. J. Pathol. 129:511-522.

12. Chevillard, M., J. Hinnrasky, J. M. Zahm, M. C. Plotkowski, and E. Puchelle. 1991. Proliferation, differentiation and ciliary beating of human respiratory ciliated cells in primary culture. Cell Tissue Res. 263:In press.

13. Colliot, G., C. Plotkowski, S. Lebonvallet, D. Altemayer, and N. Bonnet. 1990. Analyse temps réel d'images multi-échelles en microscopie électronique à balayage (MEB). Proceedings of the Congress of the French Society of Electron Microscopy.

14. Goldstein, I. J., and C. E. Hayes. 1978. The lectins: carbohydrate binding proteins of plant and animals. Adv. Carbohydr. Chem. Biochem. 35:127-340.

15. Gordon, S. R. 1988. Changes in distribution of extracellular matrix proteins during wound repair in corneal endothelium. J. Histochem. Cytochem. 36:409-416.

16. Sabet, M. D., and S. R. Gordon. 1989. Ultrastructural immunocytochemical localization of fibronectin deposition during corneal endothelial wound repair. Evidence for cytoskeletal involvement. Biol. Cell. 65:171-179.

17. Spurr-Michaud, S. J., M. Barza, and I. K. Gipson. 1988. An organ culture system for study of adherence of Pseudomonas aeruginosa to normal and wounded corneas. Invest. Ophthalmol. Visual Sci. 29:379-386.

18. Franklin, A. L., T. Todd, G. Gurman, D. Black, P. M. Mankinen-Irvin, and R. T. Irvin. 1987. Adherence of Pseudomonas aeruginosa to cilia of human tracheal epithelial cells. Infect. Immun. 55:1523-1525.

19. Niederman, M. S. T. D. Rafferty, C T Sasaki, W. W Merrill, R A Matthay, and H. Y. Reynolds. 1983. Comparison of bacterial adherence to ciliated and squamous epithelial cells obtained from the human respiratory tract. Am. Rev. Respir. Dis. 127:85-90.

20. Baker, N. R., and H. Marcus. 1982. Adherence of clinical isolates of Pseudomonas aeruginosa to hamster tracheal epithelium in vitro. Curr. Micro biol. 7:35-40.

21. Marcus, H., A. Austria, and N. R. Baker. 1989. Adherence of Pseudo monas aeruginosa to tracheal epithelium. Infect. Immun. 57:1050-1053.

22. Kim, K. C., J. I. Rearick, P. Nettesheim, and A. M. Jetten. 1985. Biochemical characterization of mucous glycoproteins synthesized and secreted by hamster tracheal epithelial cells in primary culture. J. Biol. Chem. 260:4021-4027.

23. Varsano, S., C. Basbaum, L. S. Forsberg, D. B. Borson, G. Gaughey, and J. A. Nadel. 1987. Dog tracheal epithelial cells in culture synthesize sulfated macromolecular glycoconjugates and release them from the cell surface upon exposure to extracellular proteinases. Exp. Lung Res. 13:157-184.

24. St. George, J. A., D. L. Cranz, S. C. Zicker, J. R. Etchison, D. L. Dungworth, and C. G. Plopper. 1985. An immunohistochemical characterization of 
Rhesus monkey respiratory secretions using monoclonal antibodies. Am. Rev. Respir. Dis. 132:556-563.

25. Lin, H., D. M. Carlson, J. A. St. George, C. G. Plopper, and R. Wu. 1989. An ELISA method for the quantitation of tracheal mucins from human and nonhuman primates. Am. J. Respir. Cell. Mol. Biol. 1:41-48.

26. Ericson, T., K. Pruitt and H. Wedel. 1975. The reaction of salivary substances with bacteria. J. Oral Pathol. 4:307-323.

27. Komiyama, K., B. F. Habbick, and S. K. Tumber. 1989. Whole submandibular and parotid saliva-mediated aggregation of Pseudomonas aeruginosa in cystic fibrosis. Infect. Immun. 57:1299-1304.

28. Heckman, C. A., A. C. Marchok, and P. Nettesheim. 1978. Respiratory tract epithelium in primary culture: concurrent growth and differentiation during establishment. J. Cell Sci. 32:269-291.

29. Merchant, D. J. 1990 . Terminally differentiating epithelial tissues in primary explant culture: a model of growth and development. In Vitro Cell \& Dev. Biol. 26:543-553.

30. Wong, M. K. K., and A. I. Gotlieb. 1988. The reorganization of microfilaments, centrosomes and microtubules during in vitro small wound reendothelialization. J. Cell Biol. 107:1777-1783.

31. Hergott, G. J., M. Sandig, and V. I. Kalmins. 1989. Cytoskeletal organization of migrating retinal pigment epithelial cells during wound healing in organ culture. Cell Motil. Cytoskeleton. 13:83-93.

32. Singer, S. J., and A. Kupfer. 1986. The directed migration of eukaryotic cells. Annu. Rev. Cell. Biol. 2:337-365.

33. Ramphal, R., and M. Pyle. 1983. Evidence for mucins and sialic acid as receptor for Pseudomonas aeruginosa in lower respiratory tract. Infect. Immun. 41:339-344.

34. McEachram, D. W., and R. T. Irwin. 1985. Adhesion of Pseudomonas aeruginosa to human buccal epithelial cells: evidence for two classes of receptors. Can. J. Microbiol. 31:563-569.

35. Vishwanath, S., and R. Ramphal. 1985. Tracheobronchial mucin receptor for Pseudomonas aeruginosa: predominance of aminosugars in binding sites. Infect. Immun. 48:331-335.

36. Hazlett, L. D., M. Moon, and R. S. Berk. 1986. In vivo identification of sialic acid as the ocular receptor for Pseudomonas aeruginosa. Infect. Immun. 51:687-689.

37. Hazlett, L. D., and P. Mathieu. 1989. Glycoconjugates on corneal epithelium surface: effect of neuraminidase treatment. J. Histochem. Cytochem. 37:1215-1224.

38. Reutter, W., E. Köttgen, C. Bauer, and W. Gerok. 1982. Biological significance of sialic acids. In Sialic Acids. Chemistry, Metabolism and Function. R. Schauer, editor. Springer-Verlag New York Inc. 263-305.

39. Gaillard, D. A., A. V. Lallement, A. F. Petit, and E. Puchelle. 1989. In vivo ciliogenesis in human fetal tracheal epithelium. Am. J. Anat. 185:415-428.

40. Krivan, H. C., D. D. Roberts, and V. Ginsburg. 1988. Many pulmonary pathogenic bacteria bind specifically to the carbohydrate sequence gal Nac $\beta 1-4$ gal found in some glycolipids. Proc. Natl. Acad. Sci. USA. 85:6157-6161.

41. Krivan, H. C., V. Ginsburg, and D. D. Roberts. 1988. Pseudomonas aeruginosa and Pseudomonas cepacia isolated from cystic fibrosis patients bind specifically to gangliotetraosylceramide (asialo $\mathrm{Gm}_{1}$ ) and gangliotriaosylceramide (asialo $\mathrm{Gm}_{2}$ ). Arch. Biochem. Biophys. 260:493-496.

42. Baker, N. R., and Svanborg-Eden. 1989. Role of alginate in the adherence of Pseudomonas aeruginosa. In Pseudomonas aeruginosa Infection. N. Hoiby, S. S. Pedersen, G. H. Shand, G. Döring, and I. A. Holder, editors. S. Karger AG, Basel. 72-79.

43. Panjwani, N., T. S. Zaidi, J. E. Gigstad, F. B. Jungalwala, M. Barza, and J. Baum. 1990. Binding of Pseudomonas aeruginosa to neutral glycosphingolipids of rabbit corneal epithelium. Infect. Immun. 58:114-118.

44. Singh, A., L. D. Hazlett, and R. S. Berk. 1990. Characterization of Pseudomonas aeruginosa adherence to mouse corneas in organ culture. Infect. Immun. 58:1301-1307.

45. Woods, D. E., D. C. Straus, W. G. Johanson, Jr., and J. A. Bass. 1981. Role of fibronectin in the prevention of adherence of Pseudomonas aeruginosa to buccal cells. J. Infect. Dis. 143:784-790.

46. Woods, D. E. 1987. Role of fibronectin in the pathogenesis of Gram negative bacillary pneumonia. Rev. Infect. Dis. 9 (Suppl):386-390.

47. Abraham, S. N., E. H. Beachey, and W. A. Simpson. 1983. Adherence of Streptococcus pyogenes, Escherichia coli and Pseudomonas aeruginosa to fibronectin-coated and uncoated epithelial cells. Infect. Immun. 41:1261-1268.

48. Sawada, H., H. Furthmayr, H. Konomi, and Y. Nagai. 1987. Immunoelectronmicroscopic localization of extracellular matrix components produced by bovine corneal endothelial cells in vitro. Exp. Cell Res. 171:94-109.

49. Shoji, S., K. A. Richard, R. F. Ertl, R. A. Robbins, J. Linder, and S. I. Rennard. 1989. Bronchial epithelial cells produce lung fibroblast chemotactic factor: fibronectin. Am. J. Respir. Cell. Mol. Biol. 1:13-20.

50. Hayman, E. G., and E. Ruoslahti. 1977. Distribution of fetal bovine serum fibronectin and endogenous rat cell fibronectin in extracellular matrix. $J$. Cell Biol. 83:255-259.

51. McKeown-Longo, P. J. 1987. Fibronectin-cell surface interactions. Rev. Infect. Dis. 9 (Suppl):322-334.

52. Lowrance, J. H., D. L. Hasty, and W. A. Simpson. 1988. Adherence of Streptococcus sanguis to conformationally specific determinants of fibronectin. Infect. Immun. 56:2279-2285.

53. Szczepanski, A., M. B. Furie, J. L. Benach, B. P. Lane, and H. B. Fleit. 1990. Interaction between Borrelia burgdorferi and endothelium in vitro. J. Clin. Invest. 85:1637-1647.

54. Bhaltacharyya, S. N., B. Kaufman, A. Khorrami, J. I. Enriquez, and B. Manna. 1988. Fibronectin: source of mannose in a highly purified respiratory mucin. Inflammation. 12:433-438.

55. Ruoslahti, E. 1988. Fibronectin and its receptors. Annu. Rev. Biochem. 57:375-413.

56. Kleinman, H. K., G. R. Martin, and P. H. Fishman. 1979. Ganglioside inhibition of fibronectin-mediated adhesion to collagen. Proc. Natl. Acad. Sci. USA. 76:3367-3371.

57. Thompson, L. K., P. M. Horowitz, K. L. Bentley, D. Thomas, J. F. Alderete, and R. J. Kleber. 1986. Localization of the ganglioside-binding site of fibronectin. J. Biol. Chem. 26:5209-5214. 